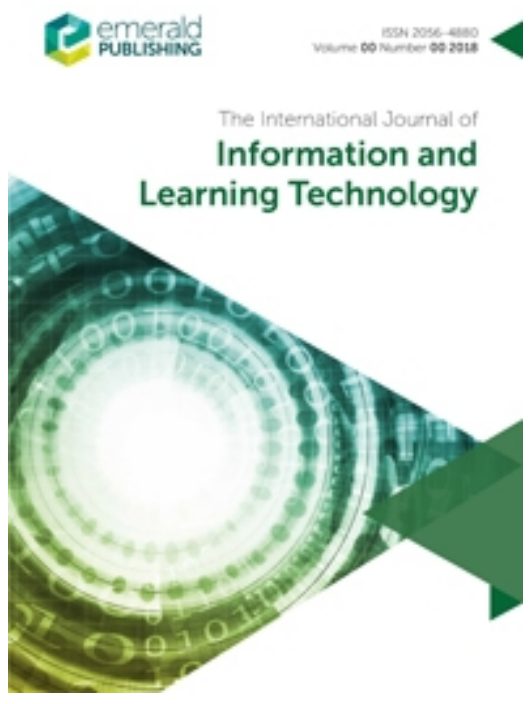

\title{
An Innovative MOOC Platform: The Implications of Self- directed Learning Abilities to Improve Motivation in Learning and to Support Self-regulation
}

\begin{tabular}{|r|l|}
\hline Journal: & International Journal of Information and Learning Technology \\
\hline Manuscript ID & IJILT-03-2020-0040 \\
\hline Manuscript Type: & Research Paper \\
\hline Keywords: & $\begin{array}{l}\text { Self-directed learning, Self-regulation learning, eLDaMOOC, MOOC, } \\
\text { Motivation, blended-learning }\end{array}$ \\
\hline \multicolumn{2}{|l}{} \\
\hline
\end{tabular}

\section{SCHOLARONE ${ }^{m}$ Manuscripts}




\title{
An Innovative MOOC Platform: The Implications of Self-directed Learning Abilities to Improve Motivation in Learning and to Support Self-regulation
}

\begin{abstract}
Massive open online courses (MOOCs) have received wide publicity and many institutions have invested considerable effort in developing, promoting and delivering such courses. However, there are still many unresolved questions relating to MOOCs and their effectiveness in a blended-learning context. One of the major recurring issues raised in both academic literature and in the press about MOOCs is the consistently high dropout rate of MOOC learners. Although many thousands of participants enroll on these courses, the completion rate for most courses is below $15 \%$. We are going to describe a new online MOOC platform called 'eLDaMOOC' ' which will be the tool for investigating self-regulated learning, and motivate continuity in the online courses to some extent. In addition, we hope to explore the self-regulated learning skills of the registered participants using a self-directed and guided course format. In the online learning environment, there are not many platforms for instance in MOOCs, that totally support learners in their self-regulated learning pace. Digital learning processes such as MOOCs recently started investigating some aspects of self-regulated learning (SRL). This study investigates and explored individual learners and students self-regulated learning skills using six dimensions: goal setting, task strategies, time management, environment structuring, help seeking and self-evaluation. The measurement instrument for this study is designed based on these six dimensions.

In this study, we applied mixed methods as an exploratory case study, which prioritised the quantitative and qualitative approaches for the data collection processes. The data were collected using a MOOC Online Self-regulated Learning Questionnaire (MOSLQ) adapted and created from an existing measuring instrument. The quantitative data was analysed using Statistical Package for the Social Sciences (SPSS Version 22) tool to conduct descriptive analysis.

The qualitative results obtained from the transcribed focus group interviews in this study, revealed the various behavioural patterns of how undergraduate students self-directed their learning. This focus group interview was conducted to reveal the various ways students organised and strategised their learning patterns in order to derive satisfaction in their distinctive learning behaviours and encourage motivation within their study approaches. Quantitative data collected online included a 30 items survey of which 17 respondents completed the survey items in the blended-learning study. The online course survey included 19 items of which data were gathered from 11 respondents. Across the data, it is noticeable and clear that time management and goal setting were among the dimensions that are highly rated close to high level among self-regulated learning skills investigated in this study. We found that goal setting and task strategies predicted much better attainment of individuals con trolling personal course goals, while help seeking was associated with lower goal attainment among majority of the participants.
\end{abstract}

Keywords - Self-directed learning, self-regulated learning, eLDaMOOC, MOOC, motivation, blended-learning

${ }^{1}$ http://eldamooc.org/ 


\section{INTRODUCTION}

MOOCs provide an innovative educational technology which has become widely used for distance learning by independent learners. There has been current research work that studied the effects of using MOOCs as part of a blended classroom approach in which learning activities take place both online and in a traditional face-to-face classroom settings (Kloos et al., 2015; Morris, 2014; Holotescu et at., 2014). This study was conducted to investigate aspects of blended MOOC usage in the context of a computing course for first year undergraduates at a top UK university in a term in the 2015/16 academic year. The MOOC was implemented on a purpose-built platform (known as eLDaMOOC) which supports learners to make informed choices about their learning path. The research investigates students' capacity for self-regulated learning (SRL) in order to understand their preparedness for independent study and to profile the general areas of SRL strength s and weaknesses, which may affect their ability to learn effectively in a self-directed MOOC environment.

Studies have soon found that most learners who registered in MOOCs engage selectively with a fraction of the course content they are interested in and dropout afterwards. In this case, we are left with only a few proportion of learners who eventually complete the course (Anderson et al., 2014; Breslow et al., 2013; Evans et al., 2016; Ho et al., 2015; Kizilcec et al., 2017). This issue of high dropout rates has been addressed in several published materials around the world. In this study, we are looking at modalities that would motivate SRL skills among students using a standalone MOOC in an online learning setting. We will present and discuss aspects on the various approaches developed by individual learners participating in the course. Students in a blended learning course, study independently with minimum supervision and they initiate a learning environment suitable to their learning abilities without much guidance.

SRL is significant in a MOOC environment with low level of guidance, the learners are able to coordinate their learning effectively and actively engage in developing SRL skills using individual initiatives. However, supporting SRL in a MOOC context involves the implementation of effective support mechanisms to support the systems to understand which SRL strategies are most effective to the current level of learning activities (Kizilcec and Halawan, 2015). Understanding the SRL level of weakness observed within individual learners could advance the provision of specific targeted support directly to the learners.

The tool with the novel features introduces paths to study in order to support self-regulated skills among the learners or students using the courses (online and blended). This research provides a pedagogical approach to creating a prototype system to aid learners in the right direction to achieve their set goals. The eLDa prototype system draws theories from other learning management systems (LMS) evaluated in the past. The major drive in this study is to investigate and understand various meta-cognitive processes of self-regulated learning occurrences using technology in educational pedagogy. This drive helped to model a more advanced prototype that was flexible with choice of mode and suitable to all learners, classes, levels and nationalities. The introduction of learning technology in education helps in supporting learning and improving how people study and engage with online content. Some research theories pointed out that commitment to online courses helps in better grades in a traditional context (Barnard-Brak et al., 2010; Nawrot and Doucet, 2014; Onah et al., 2016). In another related study, the authors argued that blended learning challenges learners' self-regulation and that this insight is significant for effective online pedagogy design (Van Laer and Elen, 2018). 
An existing survey instrument, based on a six-dimensional conceptualisation of SRL in e-learning, was adapted to investigate self-regulation in this study (Barnard et al., 2009). In order to gather useful information for investigation, in course surveys were used to obtain the self-regulated learning habit of the online course learners. Further qualitative semi-structured focus group interviews and questionnaires were conducted to support the data collection processes within the blended-classroom context. The data analysis was done with statistical analysis, thematic analysis and content analysis. Results for the whole group demonstrated that the dimensions of self-evaluation and time management represented particular areas of weakness for these students. Furthermore, profiles of SRL for individual students showed considerable differences in capability within the group. Our results show that some students and learners demonstrated distinctive high level of SRL skills within individual dimensions and need to improve in those for which they show low level of SRL skills. However, the deficiencies in SRL dimensions contrast with the students' generally high levels of attainment. This led us to question the validity of the existing conceptualisation of SRL in the context of blended-learning students. Further, a high level of social interaction and support seeking was reported in relation to MOOC study indicating the increasing importance of social learning (even within a traditional university) and the importance of co-regulation for SRL.

This study covers the areas briefly outline in the following sections; section 2 illustrates the literature review and work related to MOOCs, section 3 described the research methodologies and data collection processes, section 4 presents the result of the research from both the mixed methods of qualitative and quantitative methods, section 5 describes the conclusion and the implications of the study.

\section{Research questions}

In this study, we investigate the following research questions:

- What are the implications of self-directed learning and self-regulated learning in a MOOC context?

- What are the implications of a good design practice and implementation of instructional e-learning systems?

\section{LITERATURE REVIEW}

Educational development using technology have made online instructors and e-learning developers' training widely applicable to MOOCs. However, this validation presents some challenges, including the high level of dropout rate and low continuance and interest to study via MOOCs (Tsai et al., 2018). This lack of interest in participating in MOOCs might result from the way the course is structured and the concept of delivery that does not allow users to decide their choice of route while engaging with the course resources. According to Tsai et al., (2018), they tested students' metacognitive relationship in their learning habits, which revealed the three positive levels of learning interest to be; liking the course, enjoyment, and effective course engagement. Their findings imply that improving learners' metacognition could contribute in increasing learning interest and continuance to learn with MOOCs, thereby encouraging the benefits of reinforcing adequate instructional training and continuous professional development in order to acquire best practice skills in the development of e-learning (MOOCs) platforms. 
MOOC technology requires students to apply their metacognitive skills to manage their learning habits. Students are required to by smart, active and independent participants in maintaining their own learning progress and that could help them to reach their learning goals (Ackerman et al., 2016). Several students registered in MOOCs for various reasons, therefore if they are not motivated, they tend to dropout (Wu and Chen, 2017). While some students cannot sustain their interest in the instructional resources, others perceive this type of learning in MOOCs to be a special kind of learning experience (Chang et al., 2015). It is essential to understand the complexity involve during the learning process of students and how the technology that was adopted for teaching, could help to facilitate successful learning (Straub, 2009). Understanding and having Metacognitive knowledge is also regarded in some cases useful to instructional course developers and e-learning curriculum practitioners. This will help to facilitate adequate application of theoretical concepts into educational or pedagogical practices (Crespin and Hartung, 1997). Moreno and Mayer (2007) suggested that during learning tasks, learners' mental processes of making decisions, choices, organizing and integrating information are mediated by individual motivational factors that impact upon their metacognitive engagement with the course resources.

In a recent study, self-directed learning (SDL) and SRL are often applied to learning without clear distinction. This has been said to lead to confusion in the knowledge of appropriate tools for measurement (Gandomkar and Sandars, 2018). SDL is said to apply general approach to learning identified using questionnaires, but SRL is said to be a dynamic and context specific learning process which requires measures such as microanalysis. Although, while both concepts appear to share similarities in active learners' engagement in setting goals, making appropriate choices and implementation of suitable learning strategies, and the evaluation of learning outcomes. Nowadays, these concepts are used interchangeably in most studies. However, on intensive reviews, there are major differences within the two concepts and their implications to learning. SDL describes a general approach to learning which was adopted by the individual learners that are unique to learning habits, whereas, SRL focuses on specific key learning processes that were set based on clearly defined tasks. SRL has been said to be a critical factor in learning in both online, blended and in a traditional collaborative settings (Law et al., 2016).

Self-directed learners are said to be motivated internally and also appreciate the choice of direction for which open educational resources provided to allow learners the autonomy in their study. Self-directed learners create the opportunity to learn in an informal setting and out of their individual curiosity and interest (Jordan, 2013). These learners take absolute control of their learning and knowing that they could independently learn without any need to rely on instructors for their learning directions. According to Kizilcec and Halawa (2015), learners with strong SRL skills are characterised by their ability to plan, manage and take control of their learning process, and 'can learn faster and outperform those with weaker SRL skills'. It has been observed that learners with strong SRL skills do not only perform better, but they are more likely to revisit previous studies, assessments and learning resources that could help them to enhance better their academic performance and achievement. The behaviour of these learners are distinctive during their learning activities. This variation of learning behaviour is unique due to the diversity of learners' prior knowledge, experiences, background, interest, motivations, aspirations and intentions (de Barba et al., 2016; Jordan, 2013; Lee and Reynolds, 2015; Wang et al., 2013). Students were able to regulate their study and interact outside formal educational settings more at any time, and place of their choosing. This variation in their learning patterns provides a general enhancement to their educational experiences. 


\subsection{The emergence of MOOCs}

The evaluation of massive open online courses (MOOCs) in general has taken educational sectors by storm in the creation of open courseware (OCW) and open educational resources (OER). MOOCs are recent expansion in elearning and distance learning that have experience rapid growth and achieved high attention from large participants as compare to traditional educational system (Zheng, 2015). MOOCs demonstrates the fact that we have reach an era of open information abundance in huge contrast to information scarcity (Kolowich, 2013). Taking advantage of such open educational resources, hundreds of thousands of participants around the world enroll in courses to gain MOOCs experiences (Bowman, 2012). By early 2016, over 4,000 of such courses across a wide range of multidisciplinary subjects were made available by some MOOC platforms and providers such as Udemy, Udacity, Coursera, NovoEd, FutureLearn and edX (Bersin, 2016; Sun and Rueda, 2012; Wexler, 2015). Impressively, over 35 million participants have enrolled and participated in these courses that were delivered by educators from over 570 different universities around the world (Carter, 2016; Cook, 2016; Onah and Sinclair, 2017). Research from Shah $(2015,2016)$ and Schmid et al., (2015) indicated that MOOCs grew in 2016 to more than 58 million students who enrolled in over 7,000 MOOCs at more than 700 universities around the world. These research from the two studies present findings on the growth of MOOCs in terms of numbers from early 2015 to 2016.

Coursera is known to be the platform with the most number of registered participants. They accounted for more than 23 million MOOC participants. According to Kop et al., (2011), MOOC can provide information in some cases more than just traditional education course information and assignments. MOOC can support connections between learners and instructors in an online learning environment. When courses are design to harness information flow in the learning environment, the result can be spontaneous (MOOC@Edinburgh2013, 2013; Bonk and Lee, 2017).

MOOC received international recognition and attention especially in the Fall of 2011 where a series of MOOC platforms from Stanford University enrolled over 100,000 participants (Beckett, 2011; LittleJohn et al., 2016). There has been much attention recently related to their potential plans and sustainability in this new education paradigm and delivery (Bonk et al., 2015, 2017; Kizilcec et al., 2013; Bethke, 2016; Onah et al., 2016). Nowadays, MOOC developers are consistently considering enhancing the platform and deliberating is sues related to the accreditation, attrition, design, adaptation and personalisation (Bonk et al., 2016; Kop et al., 2011). Some of the main concerns found in this new trend of learning has to do with learners' motivation, retention and continuity (Kop et al., 2011). For example, a Bioelectricity MOOC delivered by Duke university had shown high number of registrations from participants but after few weeks, there was lack of participation in any of the course activities and high dropout rates (Belanger and Thornton, 2013; Catropa, 2013). A similar situation was observed in the six MOOCs delivered by the University of Edinburgh, which also suffered the same fate of high dropout rates and reduction in the course participation (Markoff, 2011).

Learning interest in MOOCs context may heighten overall general interest, which in most cases could improve motivation to fulfill a need for individual autonomy in e-learning systems. MOOCs is said to be mediated by the participants' learning interest developed before or while engaging with the course resources (Tsai et al., 2018). Research conducted in MOOCs using mixed methods of quantitative and qualitative approaches, has revealed that learners' reasons for attrition was related to insufficient time management skills and also on the difficulty of the course concepts (Jordan, 2013; Morrison, 2013; Wang et al., 2013). The ability to regulate learning skills in the absence of the instructor's support and guidance during learning process required critical skills from the learners in order to achieve personal learning goals. 


\section{ELDAMOOC PLATFORM}

\section{Participants and context}

This study currently has 145 registered online learners for which selected responses of 11 online samples and 27 blended-learning samples from undergraduate participants were extracted and analysed from those who participated in the Computing Concept and Python programming and the blended course delivered in the eLDa Platform. The course was offered by one of the UK top Universities, and it encompassed 7 sessions, containing at least 43 lessons embedded with video lectures and assessments (example: in lesson multiple-choice quizzes, exercises, programming activities and solutions and finally open ended and closed ended survey questions). The course assessments were not formative, therefore could only be attempted once and not multiple times as applied in another related study (Kizilcec and Halawa, 2015). The target audiences for this course were teachers of computer science education in the UK, undergraduate students, graduates and other professionals around the world who are in subject related industries. These learners responded to the early stage of the preliminary research instrument that was based on the six SRL dimensions. Indeed, based on the demographics, Table 1 shows the percentage age range of the participants. This demonstrates that early middle age participants, over $62.97 \%$ of the learners fell under the age range of $25-44$ and while the older participants from the range of 55 or over has the least percentage of $3.7 \%$.

Table 1: The Percentage Age Range of the Participants.

\begin{tabular}{|c|c|}
\hline Age Range & \multicolumn{1}{c|}{} \\
\hline $\mathbf{1 8}-\mathbf{2 4}$ & 18.52 \\
\hline $\mathbf{2 5 - 3 4}$ & 25.93 \\
\hline $\mathbf{3 5}-\mathbf{4 4}$ & 37.04 \\
\hline $\mathbf{4 5}-\mathbf{5 4}$ & 14.81 \\
\hline $\mathbf{5 5}$ or over & 3.7 \\
\hline
\end{tabular}

Further demographics reveals that $40.7 \%$ were female, $59.3 \%$ were male, $59.26 \%$ held a bachelor's or higher degrees (a Master's or Ph.D.), 11.11\% were undergraduate students from the University of Warwick, and 29.63\% were other professionals. Data were collected within a short period of time as the course was launched live for participation between January and December 2015.

\section{The eLDa self-directed scenario}

A learner registers and decides his or her learning path and pattern. The entire course content is visually displayed to the learner. The learners determine the mode in which they are interested in engaging with the course resources. In each of the seven modules in the course but one, there are five lessons apart from the introductory module that has 
three lessons, including practical exercises and solutions. Each of the modules discusses Computing Concepts and Python programming. Learners have the choice of engaging with the course by watching lecture videos, reading the text transcripts of the videos, reading the lecture resources and slides, practicing exercises and accessing external links and resources that was suggested for further clarification or enlightenment.

\section{The eLDa self-regulated scenario}

At this point, the learners prepare ahead for the lessons or modules. They set learning preferences and goals to achieve in the course. However, the researcher hoped that, with the combination of these two modes of study in the platform, learners could develop skills needed for enhancing personal or independent SRL habits. These skills will help learners to autonomously take control of their reading and improve independent learning skills.

\section{RESEARCH METHODOLOGY}

This section describes the research methodologies used in this study. This presents the methods applied to the data collection processes, and the analysis of data through the entire study. The overarching research methodology for the wider study is derived from a design science paradigm (Von Alan, et at., 2004) which was based on the development and evaluation of an innovative online and blended-learning platform to investigate and measure SRL (Barnard, et al., 2009). In this study, we applied mixed methods of qualitative and quantitative approaches for the data collection. These mixed methods were applied because the data were collected from two case studies in a stand-alone online course and a blended-learning course.

\subsection{Sampling}

This study applied two main types of sampling; convenience sampling which comprises the population of students that could be easily reached and a purposeful sampling which comprises of sample population of selected participants with common characteristics. While the convenience sampling was used for the undergraduate blendedlearning research activities, the purposeful sampling was applied for the online MOOC activities for selected teachers of computer science.

\subsection{Data collection process}

\section{Instrument and analysis}

Purposeful and convenience sampling approaches were used to select the participants for the research, as they were readily available. The data were collected using quantitative and qualitative methods. The instrument for the data collection was a MOOC Online Self-regulated Learning Questionnaire (MOSLQ), developed for a previous study (Onah et al., 2014; Onah, 2017, Barnard et at., 2009). The data were analysed using descriptive and exploratory approaches using the statistical package for the social sciences (SPSS Version 22) and R-Studio programming tool. 


\section{Focus group interviews}

A semi-structured interview format was used for the focus group discussion. The participants were divided into groups of two and the template questions were the same for both groups. The interview was recorded with three different devices in order to collate optimum data. The specific approaches used to collate the data are: (1) standard instrument to assess aspect of self-regulated learning patterns among the learners; (2) questionnaires administered to all learners collating general information of their aspirations, and experience of the course resources; (3) survey results demonstrating understanding of the course and (4) finally, a semi-structured post course focus group interviews.

\section{RESULTS}

The results from this study is gathered from a subset of learners who answered the initial entry course survey about their SRL skills and various other demographics data, their intention for participation, their motivations and preferences. Early demographic data from the blended-learning aspect of this research reveals that for majority of the undergraduate students, this is their first time in participating in a blended classroom learning. Responses from the question when students were asked if they have participated in a blended-learning course before, this reveals over $85 \%$ of the participant said they never had any blended-learning experience and only a handful of less than $15 \%$ said they had (see Figure 1). Table 2, illustrated the SRL subscale and survey questions in the MOSLQ measuring instrument.

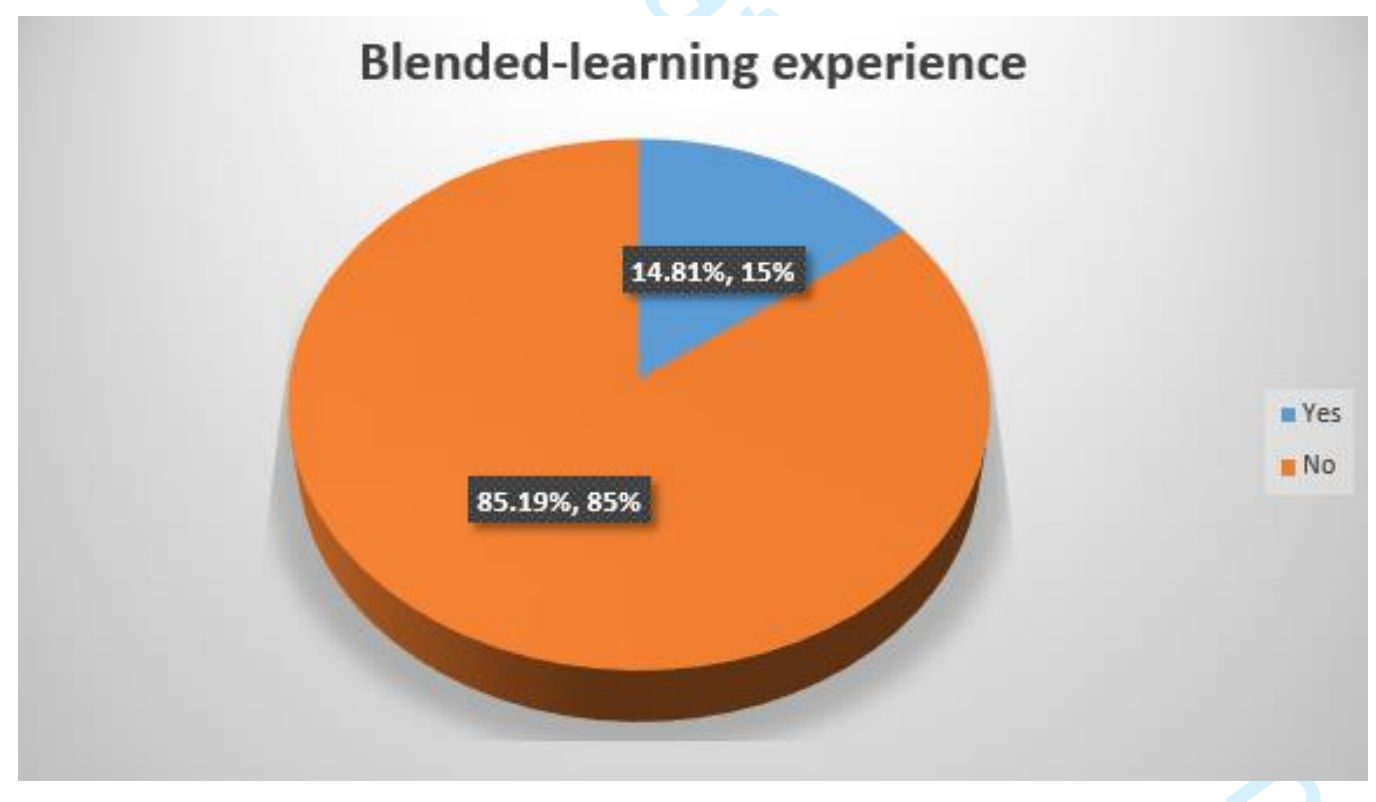

Figure 1: Show percentage of undergraduate students who has had experience in blended-learning 


\begin{tabular}{|c|c|}
\hline Subscale SRL & Survey Question \\
\hline GSQ1 & I know what I am going to achieve in this course \\
\hline GSQ2 & I have set aside time to study the course \\
\hline GSQ3 & I have high standards for my work on this course \\
\hline GSQ4 & I have set targets for all I want to achieve in this course \\
\hline GSQ5 & $\begin{array}{l}\text { I do not see my engagement in the course as less important solely because it is an } \\
\text { online course }\end{array}$ \\
\hline GSQ6 & I have written down the goals I plan to achieve by the end of this course \\
\hline TSQ1 & I work strategically to prioritise tasks to help me achieve my learning goals \\
\hline TSQ2 & $\begin{array}{l}\text { I prepare for my online study by reading the suggested background learning } \\
\text { materials beforehand }\end{array}$ \\
\hline TSQ3 & I set out my study agenda before engaging with the online resources \\
\hline TSQ4 & I am prepared to tackle any challenging aspects of the work in this course \\
\hline TMQ1 & I have planned ahead in order to devote the necessary time to my online studies \\
\hline TMQ2 & I find a good time to study when I won't be distracted \\
\hline ESQ1 & I choose my study location in order to avoid distractions \\
\hline ESQ2 & I find a comfortable place to study \\
\hline ESQ3 & I choose an appropriate place to work in order to study effectively \\
\hline HSQ1 & $\begin{array}{l}\text { I plan to use the interactive communication channels provided to gain support from } \\
\text { peers and tutors }\end{array}$ \\
\hline HSQ2 & $\begin{array}{l}\text { I plan to participate in the course discussion forums in order to get the most out of } \\
\text { the course }\end{array}$ \\
\hline SEQ1 & While engaging in this course, I will reflect on my study in each module \\
\hline SEQ2 & I will be proactive in engaging and reviewing progress in the learning path I select \\
\hline
\end{tabular}

\subsection{Results by individual questions}

Table 3 reveals the mean and standard deviation of the survey questions of the MOSLQ instrument. As can been seen, this shows variation in the mean responses from GSQ4: 2.18 to SEQ2: 4.18 indicating that some areas of the SRL are better advanced than the others, therefore, there are needs for improvements in these less developed aspects of SRL skills. These individual questions contribute to the six SRL dimensions in this study. Table 3 shows the results arranged according to the subscale of these dimensions, which revealed a noticeable variation between the mean and standard deviation of each. The respondents self-reported effective results at self-evaluation (SEQ1 and SEQ2), which reveals that participants reflect on their own learning and evaluate their progress. Individual participants in this study show effective goal setting skills in the aspect of (GSQ1, GSQ2, GSQ3, GSQ4 and GSQ5). 
This shows that majority of the individuals in this study set goals and work towards achieving the results to attain better outcomes. For a sub-scale dimension question to be classified as high SRL skills, the mean should be from 3.5 to 4.18 , any average below the threshold of 3.5 is considered in this study has low SRL skills. A few SRL questions achieved this result, therefore indicated that there is a necessity for improve achievement in all the aspects below the threshold. This study shows alarming and concerning results in help seeking and task strategies among the learners. It might be that the learners do not expect this instrument questions in aspect of help seeking and task strategies to be attributed to an effective means for them to study and achieve success.

Table 3: Survey instrument questions mean and standard deviation of the SRL dimensions.

\begin{tabular}{|l|c|l|}
\hline Subscale SRL & Mean & Standard Deviation \\
\hline GSQ1 & 3.55 & 1.128 \\
\hline GSQ2 & 3.45 & 0.688 \\
\hline GSQ3 & 3.82 & 0.603 \\
\hline GSQ4 & 3.00 & 1.0 \\
\hline GSQ5 & 4.09 & 0.831 \\
\hline GSQ6 & 2.18 & 0.874 \\
\hline TSQ1 & 3.82 & 0.603 \\
\hline TSQ2 & 2.91 & 1.221 \\
\hline TSQ3 & 2.36 & 0.924 \\
\hline TSQ4 & 2.82 & 0.874 \\
\hline TMQ1 & 2.73 & 0.905 \\
\hline TMQ2 & 4.09 & 0.831 \\
\hline ESQ1 & 3.73 & 0.905 \\
\hline ESQ2 & 3.91 & 0.701 \\
\hline ESQ3 & 3.36 & 0.924 \\
\hline HSQ1 & 2.55 & 0.082 \\
\hline HSQ2 & 2.27 & 0.905 \\
\hline SEQ1 & 3.91 & 0.539 \\
\hline SEQ2 & 4.18 & 0.603 \\
\hline
\end{tabular}




\subsection{Results from focus group interviews}

This section presents results from the focus group interview conducted for first year undergraduate blended-learning students from a top UK University. We demonstrate the emerging themes extracted from the transcribed interviews and responses. Deductive themes were derived from the six SRL dimensions in this study that were extremely relevant to report in this research (see Table 4).

Goal Setting: This theme revealed responses to when students were asked how they prepared for their studies, over $70 \%$ of the emerging themes was related to having interest in the course, learning, understanding and meeting deadlines. Over $24 \%$ said they prepared for their studies for the sake of obtaining a better result and the level of motivation the get from the course.

Task Strategies: This theme focused on the strategies students used in their studies. Results shows that over $59 \%$ of the students said they listen to music, adequately planned and prepared for their studies and constantly read their learning resources. About $21.88 \%$ said they revise, draw and rewrite their lecture notes while $18.76 \%$ said the play computer games and afterwards engage in studies according to their learning priority and also on how important this is to their discipline.

Time Management: This theme illustrated how students allocate time to their studies. Over 90\% allocate time for their studies according to how important the resources are, prioritise their studies to cover topic areas of interest and work under-pressure to meet their closest deadline.

Environment Structuring: In this theme, about $34.62 \%$ revealed that students preferred a learning environment that is silent, tidy and with less distractions, $26.96 \%$ preferred a learning environment that will make them to be more focused to concentrate on their studies, while about $30 \%$ preferred their learning environment to have people, so they could interact and be motivated to study.

Help Seeking: This revealed emerging themes of the various ways that students seek for help with their studies. Over $48 \%$ seek help from friends, within group studies and from the library. Over $51 \%$ seek help with their studies from Google, YouTube, the Internet and online.

Self-Evaluation: In this theme, over $46 \%$ revealed that students self-reflect in their studies when they received their assessment and examination scores. Students' self-reflection during 
their studies, shows over 53\% reflect when evaluating their studies, when listening to lectures, and also they reflect when revising their learning resources.

Table 4: Deductive themes derived from the focus group interviews

\begin{tabular}{|c|c|c|c|c|c|}
\hline 8 & & Deductive & Themes & & \\
\hline $\begin{array}{l}\text { Theme: Goal S } \\
\text { Sub-theme: } P r \\
\text { studies }\end{array}$ & $\begin{array}{l}\text { paration for } \\
\text { paring }\end{array}$ & $\begin{array}{l}\text { Theme: Task S } \\
\text { Sub-theme: St } \\
\text { used in studies }\end{array}$ & $\begin{array}{l}\text { rategies } \\
\text { tegies }\end{array}$ & $\begin{array}{l}\text { Theme: Tim } \\
\text { Sub-theme } \\
\text { studies }\end{array}$ & $\begin{array}{l}\text { Management } \\
\text { Allocating time for }\end{array}$ \\
\hline Emerging & $\begin{array}{c}\text { Percent } \\
(\%)\end{array}$ & Emerging & $\begin{array}{c}\text { Percent } \\
(\%)\end{array}$ & Emerging & $\begin{array}{c}\text { Percent } \\
(\%)\end{array}$ \\
\hline Deadline & 17.14 & Draw-Notes & 6.25 & Important & 30 \\
\hline Interest & 20 & Games & 9.38 & Prioritise & 30 \\
\hline Learning & 20 & Music & 18.75 & Schedule & 10 \\
\hline Motivation & 11.43 & $\begin{array}{l}\text { Planned \& } \\
\text { Prepare }\end{array}$ & 18.75 & $\begin{array}{l}\text { Under- } \\
\text { pressure }\end{array}$ & 30 \\
\hline Results & 14.29 & Priority & 9.38 & & \\
\hline Understanding & 17.14 & Reading & 21.88 & & \\
\hline & & Revise & 9.38 & & \\
\hline & & Rewrite-Notes & 6.25 & & \\
\hline $\begin{array}{l}\text { Theme: Enviro } \\
\text { Structuring } \\
\text { Sub-theme: } P r \\
\text { learning enviro }\end{array}$ & $\begin{array}{l}\text { iment } \\
\text { ferred } \\
\text { nment }\end{array}$ & $\begin{array}{l}\text { Theme: Help S } \\
\text { Sub-theme: } W c \\
\text { seeking help }\end{array}$ & $\begin{array}{l}\text { eking } \\
\text { ys of }\end{array}$ & $\begin{array}{l}\text { Theme: Self } \\
\text { Sub-theme: } \\
\text { during studi }\end{array}$ & $\begin{array}{l}\text {-Evaluation } \\
\text { Self-reflection }\end{array}$ \\
\hline Emerging & $\begin{array}{c}\text { Percent } \\
(\%)\end{array}$ & Emerging & $\begin{array}{c}\text { Percent } \\
(\%)\end{array}$ & Emerging & $\begin{array}{c}\text { Percent } \\
(\%)\end{array}$ \\
\hline $\begin{array}{l}\text { Less } \\
\text { distraction }\end{array}$ & 11.54 & Friends & 14.81 & Assessment & 28.57 \\
\hline Focus & 26.92 & Google & 11.11 & Evaluate & 10.71 \\
\hline Not quiet & 7.69 & Group study & 22.22 & Exams & 17.86 \\
\hline Silent & 11.54 & $\begin{array}{l}\text { Internet \& } \\
\text { Online }\end{array}$ & 33.33 & Listening & 14.29 \\
\hline Tidy & 11.54 & Library & 11.11 & Reflecting & 14.29 \\
\hline With people & 30.77 & YouTube & 7.41 & Revising & 14.29 \\
\hline
\end{tabular}




\subsection{Visualisation of SRL subscale results}

Figure 2 illustrates the distinctive levels of SRL skills observed from the six dimensions in this study. The results reveal high levels of SRL skills in some of the dimensions while there is need for improvement within some of the other dimensions. For example, goal setting demonstrates a high score within the Likert scale responses and others are relatively low. The help seeking dimension shows that there is a need for improvement among this dimension. This could be enhanced as learners develop the habits and skills for asking for support with their studies either from tutors or from classmates. The results indicated the respondents' responses to the individual questions and indicate aspects of SRL questions that are under-represented in this study. Although two or more learners may have similar response patterns, but their individual profiles may differ considerable with each showing different weaknesses and strengths within the dimensions. There is need to apply different approaches to provide effective support to learners in order to improve those dimensions or strategies that were identified to be weak.

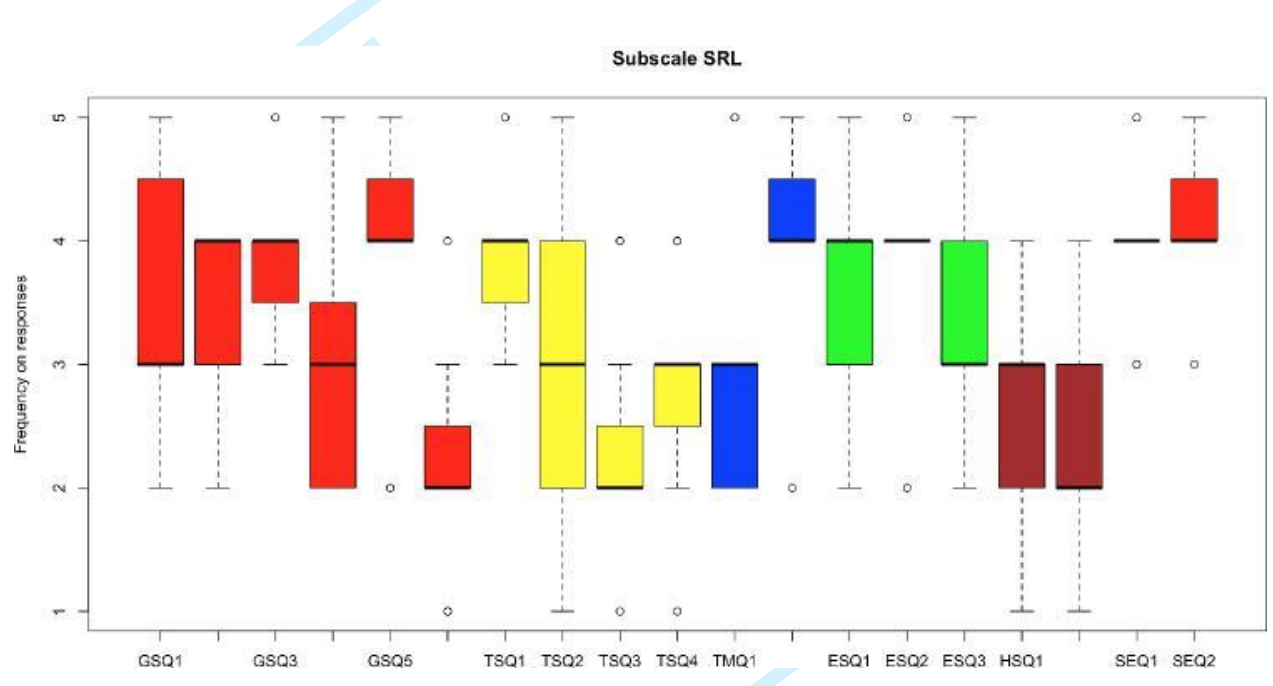

Figure 2: Visualisation of Subscale of SRL skills.

\section{CONCLUSION}

Compared to instructional classes, contemporary online environments tend to provide less support to the learners and directions on how to learn effectively. Online learners are supposed to actively engage in their studies and autonomously take control of their learning process, which adequately demand a high degree of confidence in their learning abilities and in the abilities to manage their learning progresses. Current MOOC systems fail to consider good aspects of effective support and learning pedagogy, which has been established in traditional educational setting to be beneficial for teaching and learning. With the didactic nature of MOOC one-size-fitsall approaches, they lack the full flexibility structure to aid effective engagement that allow the learners to direct and regulate their learning. There is a need for learners to be provided with the opportunity of making their own individual choices and deciding unique route that could motivate them in learning, and encourage continuous engagement in a MOOC. This study supports the fact that most MOOC learners are highly educated practitioners 
with adequate skills to regulate their learning process. However, our results indicate that these learners did not show high level of skills as might be expected within the SRL subscale questions at an acceptable high level individually. In particularly, task strategies and help seeking items revealed low responses within the instrument questions as used in this study. Therefore, we could not conclude that even practitioners and highly educated professionals who are learners in a MOOC context could regulate their learning effectively. There is need for MOOC to incorporate modalities of engaging and encouraging self-regulated learning skills among participants.

\subsection{Implications of the study}

In this study, we discovered that most of the learners were keen to direct their own individual learning path and those who followed the instructional path engaged with the course as suitable to their learning habits. Thus, these learners were showing their abilities for autonomous learning skills and taking control to achieve individual learning goals. Our platform currently allows learners to direct their learning within the course and also allow the choice of content prerequisite in order to recommend resources necessary for their learning. This study indicates the necessity to support SRL skills and directing development of self-determination skills among the participants. This study when applied to a larger sample will demonstrate effective measurement on areas of reliability and validity as results from this small sample has indicated some high SRL skill levels for individual learners within the research.

The study also identified several challenges. For example, there were some challenges in learners completing the survey questions even when several reminders were sent out forth nightly. At this preliminary stage, learners participated as lurkers without engaging fully with other non-academic and academic interactive activities such as surveys, in course quizzes and forums. Most of the participants in this course said they enrolled to know more about the new trend MOOC, to make friends, to have fun and so on. Although, these are some of their intentions for participating, some of the participants at some points contributed to discussion forums. The results from this study's investigation reveals distinctive SRL skills among the learners. There are some dimensions that shows high SRL skills and while others show low SRL skills, which necessitate further improvement among the participants. The participants' intentions are as important in this study as well as their distinctive independent SRL skills. In this study, we hoped to reveal high levels of SRL skills among the participants, due to the fact that majority of those involved in the study were highly educated. However, this is not fully the case in our investigation, as most of the learners preferred to go 'solo' in this study without seeking help in most cases and preferred independent learning habits. This attribute leads to the low level of help seeking as revealed in Table 3 in the results section. Although this preliminary study and results are only from a small group of respondents who participated in the course, the results indicated areas for our further investigation.

The study presented results from a small sample of participants in the stand-alone MOOC platform. However, this has exposed emerging themes that are of interest and which could be further investigated. In addition, we will explore other new approaches to harness the means of supporting learners developing SRL skills.

\subsection{E-learning design implications for practitioners}

There are many e-learning platforms in existence globally, but little has been mentioned about the development of a MOOC platform in general that could allow independent learning, and also adequately demonstrating the components and features used in these MOOC designs. This research's implication is to aid instructional designers to apply best practices in the development of an online course. The best approach in designing a good course is to consider the learners and how they could engage with the course resources 
independently and develop the ability to self-direct their learning. One of the main goals of e-learning platforms is primarily based on developing learning resources that would be suitable for linear course structure as directed by the course developer or instructor. In order to include best practices in e-learning development, some course instructors have constantly revised their content to improve the learning structure, deliver better interactive courses, and ensure learners attain optimum satisfaction from the learning platform resources (Alexander, 2001).

However, the success of any e-learning or MOOC platform should consider the following best practices and objectives: the learners' entire learning experience, the strategies used in developing the course content, the planning of the course delivery, and the methods of delivery. Therefore, all e-learning platforms should be designed with a primary focus on the way students learn to improve their own learning skills and help them regulate their own independent learning habits (Littlejohn, 2015). In another related study, the success of any e-learning course implementation should be carefully considered with regards to the course's underlying pedagogy and how learners engage with the content (Govindasamy, 2001). However, this is one of the most important factors that have been lacking in most MOOC learning or e-learning platforms and their evaluation.

\subsection{Recommendation and future work}

In line with a design base research approach, our future research development plan is in the direction of investigating ways of motivating self-directed learning habits. Looking at ways of improving effective interactive learning to elevate help-seeking skills. In line with this proposed future work, we hope to increase learners' awareness of the need to improve on these SRL skills, and also develop additional skills for setting up achievable goals to pursue.

\section{ACKNOWLEDGMENT}

The first author wishes to acknowledge Mr. Adakole S. Onah's financial support in his research, family members and friends for their moral support.

\section{COMPLIANCE WITH ETHICAL STANDARDS}

\section{Funding and Conflict of Interest}

There are no funding and conflict of interest attached to this research. The research work and outcomes were supported by a self-funded researcher and family.

\section{Research involving human participants}

With diligent consideration and with the permission of the student participants, the authors applied a careful approach and tag anonymously all the feedback analysis with no subject to any one single individual student in the class. We understood the ethical implications involved in reviewing individual confidential feedback for public information. The authors do have full responsibility for all information contained here.

\section{Informed consent}

The authors declared that appropriate ethical concepts and full approval were given by the host institution to conduct the research. 


\section{REFERENCES}

Ackerman, R., Parush, A., Nassar, F., \& Shtub, A. (2016). Metacognition and system usability: Incorporating metacognitive research paradigm into usability testing. Computers in Human Behavior, 54, 101-113.

Anderson, A., Huttenlocher, D., Kleinberg, J., and Leskovec, J. (2014). Engaging with massive online courses. In Proceedings of the 23rd international conference on World wide web, pages 687-698. ACM.

Barnard, L., Lan, W. Y., To, Y. M., Paton, V. O., \& Lai, S. L. (2009). Measuring self-regulation in online and blended learning environments. The internet and higher education, 12(1), 1-6.

Barnard-Brak, L., Paton, V. O., and Lan, W. Y. (2010). Profiles in self-regulated learning in the online learning environment. The International Review of Research in Open and Distributed Learning, 11(1):61-80.

Beckett, J. (2011). Free computer science courses, new teaching technology reinvent online education. Standford University News. Available at: http://news.standford.edu/news/2011/august/onlinecomputer-science-081611.html, Accessed: 11 June 2017.

Belanger, Y. and Thornton, J. (2013). Bioelectricity: A quantitative approach duke university's first mooc.Available at: https://dukespace.lib.duke.edu/dspace/bitstream/handle/10161/6216/

Duke Bioelectricity MOOC Fall2012.pdf, Accessed: 11 June 2017.

Bersin, J. (2016). Use of MOOCs and online education is exploding: Here's why. Available at: https://pittcoursera.wordpress.com/2016/01/05/moocs-and-online-educationexploding/, Accessed: 11 June 2017.

Bethke, R. (2016). Developing country mooc users not like those in the u.s. Available at: https://www.ecampusnews.com/top-news/developing-country-mooc/, Accessed: 11 June 2017.

Bonk, C. J., Lee, M., Reeves, T. C., and Reynolds, T. H. (2016). The emergence and design of massive open online courses. In R.A. Reiser \& J.V. Dempsey (Eds.), Trends and issues in instructional design and technology (4th Ed.), 1:250-258.

Bonk, C. J. and Lee, M. M. (2017). Motivations, achievements, and challenges of self-directed informal learners in open educational environments and MOOCs. Journal of Learning for Development-JL4D, 4(1).

Bonk, C. J., Lee, M. M., Reeves, T. C., and Reynolds, T. H. (2015). MOOCs and open education around the world. London; New York: Routledge.

Bowman, K. D. (2012). Winds of change: Is higher education experiencing a shift in delivery. Public Purpose Magazine( from the American Association of State Colleges and Universities).

Breslow, L., Pritchard, D. E., DeBoer, J., Stump, G. S., Ho, A. D., and Seaton, D. T. (2013). Studying learning in the worldwide classroom: Research into edx's first MOOC. Research 4 Practice in Assessment, 8. 
Carter, J. (2016). Mooc and learn: The university with 35 million students. techradar. Available at: http://www.techradar.com/news/world-of-tech/mooc-and-learn-the-university-with-35-millionstudents-1318037, Accessed: 11 June 2017.

Catropa, D. (2013).Big (mooc) data. inside higher education. Available at : https://www.insidehighered.com/blogs/stratedgy/big-mooc-data, Accessed: 11 June 2017.

Chang, R. I., Hung, Y. H., \& Lin, C. F. (2015). Survey of learning experiences and influence of learning style preferences on user intentions regarding MOOCs. British Journal of Educational Technology, 46(3), 528-541.

Cook, M. (2016).State of the mooc 2016: A year of massive landscape change for massive open online courses. online course report, march. Availabe at: http://www.onlinecoursereport.com/state-of-themooc-2016-a-year-of-massive-landscape-change-for-massive-open-online-courses/, Accessed: 11 June 2017.

Crespin, L., \& Hartung, E. (1997). Metacognition as a Necessary Strategy for Teacher Training in DBAE: Facilitating Theory into Practice. Visual Arts Research, 124-134.

de Barba, P. G., Kennedy, G. E., and Ainley, M. D. (2016). The role of students' motivation and participation in predicting performance in a mooc motivation and participation in MOOCs. Journal of Computer Assisted Learning.

Alexander, S. (2001) E-learning developments and experiences. Education + Training, 43(4/5):240248.

Evans, B. J., Baker, R. B., and Dee, T. S. (2016). Persistence patterns in massive open online courses (MOOCs). The Journal of Higher Education, 87(2):206-242.

Gandomkar, R., \& Sandars, J. (2018). Clearing the confusion about self-directed learning and selfregulated learning. Medical teacher, 1-2.

Govindasamy, T. (2001). Successful implementation of e-learning: Pedagogical considerations. The internet and higher education, 4(3-4), 287-299.

Ho, A. D., Chuang, I., Reich, J., Coleman, C. A., Whitehill, J., Northcutt, C. G., Williams, J. J., Hansen, J. D., Lopez, G., and Petersen, R. (2015). Harvardx and mitx: Two years of open online courses fall 2012-summer 2014. SSRN Electronic Journal, 10(1-37).

Holotescu, C., Grosseck, G., CREŢU, V., \& Naaji, A. (2014). Integrating MOOCs in Blended Courses. Elearning \& Software for Education, (1).

Jordan, K. (2013). MOOC completion rates: The data. Available at: http://www.katyjordan.com/MOOCproject.html. Accessed : 24 June 2017.

Kizilcec, R. F. and Halawa, S. (2015). Attrition and achievement gaps in online learning. In Proceedings of the Second (2015) ACM Conference on Learning@ Scale, pages 57-66. ACM. 
Kizilcec, R. F., Pérez-Sanagust'1n, M., and Maldonado, J. J. (2017). Self-regulated learning strategies predict learner behavior and goal attainment in massive open online courses. Computers 4 Education, 104:18-33.

Kizilcec, R. F., Piech, C., and Schneider, E. (2013). Deconstructing disengagement: analyzing learner subpopulations in massive open online courses. In Proceedings of the third international conference on learning analytics and knowledge, pages 170-179. ACM.

Kloos, C. D., Muñoz-Merino, P. J., Alario-Hoyos, C., Ayres, I. E., \& Fernández-Panadero, C. (2015, March). Mixing and blending MOOC Technologies with face-to-face pedagogies. In 2015 IEEE Global Engineering Education Conference (EDUCON) (pp. 967-971). IEEE.

Kolowich, S. (2013).How edx plans to earn, and share, revenue from its free online courses.The Chronicle of Higher Education. Available at: http://chronicle.com/article/How-EdX-Plans-to-Earnand/137433/, Accessed: 11 June 2017, 21.

Kop, R., Fournier, H., and Mak, J. S. F. (2011). A pedagogy of abundance or a pedagogy to support human beings? participant support on massive open online courses. The International Review Of Research In Open And Distributed Learning, 12(7):74-93.

Law, V., Ge, X., \& Eseryel, D. (2016). The development of a self-regulation in a collaborative context scale. Technology, Knowledge and Learning, 21(2), 243-253.

Lee, M. and Reynolds, T. (2015). Moocs and open education: The unique symposium that led to this special issue. International Journal on E-Learning, 14(3):279-288.

Littlejohn, A., \& Milligan, C. (2015). Designing MOOCs for professional learners: Tools and patterns to encourage self-regulated learning. eLearning Papers, 42 ,(4): 1-10.

Littlejohn, A., Hood, N., Milligan, C., and Mustain, P. (2016). Learning in MOOCs: Motivations and self-regulated learning in MOOCs. The Internet and Higher Education, 29:40-48.

Markoff, J. (2011). Virtual and artificial, but 58,000 want course. The New York Times. Available at: http://www.nytimes.com/2011/08/16/science/16stanford.html, Accessed: 11 June 2017, 15.

MOOC@Edinbungh2013(2013).Mooc@edinbungh2013repa\#l-university of edinburgh, edinburgh, scotland.Available at : https://www.era.lib.ed.ac.uk/bitstream/handle/1842/6683/Edinburgh MOOCs Report2013 no1.pdf? Accessed: 11 June 2017.

Moreno, R., \& Mayer, R. (2007). Interactive multimodal learning environments. Educational psychology review, 19(3), 309-326.

Morris, N. P. (2014). How Digital Technologies, Blended Learning and MOOCs Will Impact the Future of Higher Education. International Association for the Development of the Information Society.

Morrison, D. (2013). The ultimate student guide to xMOOCs and cMOOCs. Available at: http://moocnewsandreviews. com/ultimate-guide-to-xmoocsand-cmoocso, Accessed: 11 June 2017. 
Nawrot, I. and Doucet, A. (2014). Building engagement for mooc students: introducing support for time management on online learning platforms. In Proceedings of the 23rd International Conference on World Wide Web, pages 1077-1082. ACM.

Onah, D. F. O. (2017). Investigating self-regulated learning in massive open online courses: a design science research approach (Doctoral dissertation, University of Warwick).

Onah, D. F. and Sinclair, J. (2016). An empirical investigation of students' perceptions of self-regulated learning in online blended learning: a case study of a novel e-learning platform. EDULEARN16 Proceedings, pages 5960-5969.

Onah, D. F., Sinclair, J., \& Boyatt, R. (2014). Dropout rates of massive open online courses: behavioural patterns. EDULEARN14 proceedings, 5825-5834.

Onah, D. F., Sinclair, J., Pang, E. L., and Jantjies, M. (2016). Exploring the multi-dimensional attainment of self-regulatory learning skills in educational contexts: a comparative study. EDULEARN16 Proceedings, pages 5970-5979.

Onah, D. F. O. and Sinclair, J. E. (2017). Assessing self-regulation of learning dimensions in a standalone mooc platform. International Journal of Engineering Pedagogy (iJEP), 7(2):4-21.

Schmid, L., Manturuk, K., Simpkins, I., Goldwasser, M., and Whitfield, K. E. (2015). Fulfilling the promise: do MOOCs reach the educationally underserved? Educational Media International, 52(2):116-128.

Shah, D. (2015). By the numbers: Moocs in 2015. class central. Available at: https://www.classcentral.com/report/moocs-2015-stats/,Accessed: 11 June 2017.

Shah, D. (2016). By the numbers: Moocs in 2016. class central. Available at: https://www.classcentral.com/report/mooc-stats-2016/, Accessed: 11 June 2017.

Straub, E. T. (2009). Understanding technology adoption: Theory and future directions for informal learning. Review of educational research, 79(2), 625-649.

Sun, J. C.-Y. and Rueda, R. (2012). Situational interest, computer self-efficacy and self-regulation: Their impact on student engagement in distance education. British Journal of Educational Technology, 43(2):191-204.

Tsai, Y. H., Lin, C. H., Hong, J. C., \& Tai, K. H. (2018). The effects of metacognition on online learning interest and continuance to learn with MOOCs. Computers \& Education.

Van Laer, S., \& Elen, J. (2018). Adults' self-regulatory behaviour profiles in blended learning environments and their implications for design. Technology, Knowledge and Learning, 1-31.

Von Alan, R. H., March, S. T., Park, J., \& Ram, S. (2004). Design science in information systems research. MIS quarterly, 28(1), 75-105.

Wang, C.-H., Shannon, D. M., and Ross, M. E. (2013). Students' characteristics, self-regulated learning, technology self-efficacy, and course outcomes in online learning. Distance Education, 34(3):302-323. 
Wexler, E. (2015). Moocs are still rising, at least in numbers. the chronicle of higher education. Available at: http://www.chronicle.com/blogs/wiredcampus/moocs-are-still-rising-at-least-innumbers/57527, Accessed: 11 June 2017.

Wu, B., \& Chen, X. (2017). Continuance intention to use MOOCs: Integrating the technology acceptance model (TAM) and task technology fit (TTF) model. Computers in Human Behavior, 67, 221-232.

Zheng, S., Rosson, M. B., Shih, P. C., and Carroll, J. M. (2015). Understanding student motivation, behaviors and perceptions in moocs. In Proceedings of the 18th ACM conference on computer supported cooperative work \& social computing, pages 1882-1895. ACM. 